\title{
A Pesquisa na Saúde e Suas Limitações: a Questão do Erro Médico
}

\section{Research in Health and Its Limitations: the Issue of Medical Error}

Vitor Silva Mendonça ${ }^{I}$

\section{PALAVRAS-CHAVE}

- Erros Médicos;

- Pesquisa Qualitativa;

- Métodos;

- Educação Médica.

\section{KEYWORDS}

- Medical Errors;

- Qualitative Research;

- Methods;

- Medical Education.

\section{RESUMO}

Esse texto mostra a importância de apontar as dificuldades de uma pesquisa com tema tão delicado e ao mesmo tempo relevante para a atualidade. Descrevem-se alguns entraves que o pesquisador pode encontrar ao desenvolver sua pesquisa, reforçando a carência desse tipo de publicação no meio científico e almejando uma impulsão nas discussões sobre dificuldades metodológicas na educação médica.

\begin{abstract}
This paper demonstrates the importance of pointing out the difficulties of a research study focused on a subject matter which is both highly sensitive and relevant to the modern world. Some obstacles that may confront the researcher during the development of the study are described, underlining the lack of this kind of publication in the scientific community and aiming to drive discussions regarding methodological difficulties in medical education.
\end{abstract}

ABSTRACT 
A arte de fazer pesquisa no Brasil e no mundo não é uma tarefa simples, principalmente quando o tema apresenta grandes discussões em seu entorno e envolve aspectos delicados como o sofrimento humano. Assim, pesquisar o erro médico em nosso país é uma tarefa que impõe dificuldades além do esperado. Por isso, é fundamental compartilhar com a comunidade acadêmica os percalços desta pesquisa em desenvolvimento no Instituto de Psicologia da Universidade de São Paulo (USP).

O consumo dos recursos médicos pela população brasileira vem crescendo, assim como a utilização de novas tecnologias diagnósticas e terapêuticas que visam a melhorias da saúde. Paralelamente, crescem também os denominados eventos adversos, mais comumente chamados de erros médicos, durante ou após a assistência ao paciente ${ }^{1}$.

O erro médico pode ser entendido e conceituado como "[...] a conduta profissional inadequada que supõe uma inobservância técnica, capaz de produzir dano à vida ou agravo à saúde de outrem, mediante imperícia, imprudência ou negligência"1 (p. 27).

Hoje, a ocorrência de erros médicos tem tomado grandes proporções, principalmente pela influência da mídia, que desencadeia uma forte pressão para se descobrir o culpado e a causa do erro ${ }^{2}$, deixando em segundo plano, ou mesmo de lado, a dimensão experiencial da própria vítima do erro médico. Por conta disso, o autor desta comunicação iniciou uma pesquisa qualitativa a fim de verificar com pessoas vítimas de erros médicos a dimensão experiencial e vivencial de cada história marcada pelo erro. Muitas barreiras, entraves e dificuldades foram surgindo no desenrolar do estudo. Dessa maneira, percebeu-se a importância de verbalizar e compartilhar com os demais pesquisadores, aspirantes ou não, esse momento tão particular de uma pesquisa.

Portanto, o objetivo desta comunicação é apontar as dificuldades impostas a uma pesquisa na área da saúde, especificamente no momento da coleta dos dados, sobre a temática do erro médico em nosso país. Esta pesquisa foi aprovada pelo Comitê de Ética em Pesquisa com Seres Humanos da Faculdade de Saúde Pública da USP e está registrada sob o protocolo 2277, que inclui um projeto maior com a finalidade de estudar o erro médico.

A coleta de dados é uma parte imprescindível de qualquer pesquisa científica, porém alguns imprevistos são incontroláveis e podem provocar um desvio no caminho planejado pelo pesquisador. O momento de chegar até o participante vítima de erro médico foi um tanto dolorido e árduo.

Todo o planejamento do pesquisador para acessar uma organização não governamental ou conseguir ajuda de pessoas com trabalho social nessa área foi desconstruído a cada barreira imposta. Inicialmente, as dificuldades encontradas estavam em torno das ONGs situadas no Estado de São Paulo com o trabalho voltado para o erro médico. Em quase todas elas, o contato foi bem difícil. Quando se conseguia chegar até o responsável, nada acontecia. Numa dessas organizações, foram agendadas mais de três reuniões para expor a pesquisa, e em nenhuma delas o responsável compareceu, embora sempre tenha confirmado a presença.

Outro impedimento encontrado foi no campo do jornalismo. Essa área também era um dos caminhos que o pesquisador tentaria trilhar para alcançar algumas pessoas que pudessem relatar sua experiência. Todavia, todas as emissoras, canais e sites consultados foram categóricos ao afirmarem que nenhuma informação sobre as reportagens poderia ser divulgada, tendo em vista a privacidade da fonte coletada.

Mais tarde, conseguiu-se chegar a um advogado que prontamente foi simpático e categórico no apoio e incentivo a esta pesquisa, principalmente por se poder desvelar o sofrimento dessas vítimas. Um participante foi "perdido" no momento da marcação do primeiro contato, devido à morte ocorrida por erro médico. Aqui ficou visível o quanto a pesquisa é importante, e as grandes dificuldades não impediriam o desenvolvimento do trabalho. Nesse momento, pensou-se em quantas vítimas e famílias estão sofrendo por conta de um erro. Se elas mal conseguem lutar pelo seu direito, que dizer sobre seu sofrimento?

Grande parte das pessoas chegou até a pesquisa por meio do efeito "bola de neve", ou seja, uma pessoa que sabia da existência da pesquisa, ou de uma vítima, passa a informação adiante até chegar ao pesquisador. Logo, eram pessoas indicadas à pesquisa. Algumas delas já tiveram seus casos relatados na mídia e, quando abordadas para participar deste estudo, diziam que estavam expostas demais com a repercussão do caso e que não gostariam de participar, porque, se com a reportagem nada aconteceu, por que com esta pesquisa seria diferente? Esta foi uma indagação ouvida com frequência pelo pesquisador, que tentava justificar, mas em vão.

Alguns outros possíveis participantes eram impedidos por seus advogados, com a justificativa de ficarem expostos, de não ser bom para o processo na Justiça, de atrapalhar o andamento do caso, ou até mesmo por medo ou ameaça. É preciso ficar claro que, na maioria dos casos em que a vítima tinha um advogado que a representasse judicialmente, o pesquisador fazia questão de contatá-lo primeiro. Um caso específico foi de um possível participante do sexo masculino, vítima de erro médico em um hospital privado de renome no cenário nacional, que foi indicado ao pesquisador pelo método "bola de neve". O pesquisador fez questão de informar o advogado 
da vítima, mas ela própria relatou não haver necessidade, afirmando que posteriormente falaria, e assim ficou tudo acertado para o depoimento. No dia do encontro, essa vítima avisa que não poderia mais comparecer, uma vez que o advogado a aconselhou a não participar, pelo simples motivo de o caso ter sido levado a um acordo financeiro do hospital com a vítima, e esta última se comprometeu a não entrar com processo na Justiça comum. Seu tratamento para reparo do erro seria realizado com o custeio do próprio hospital. Dessa forma, essa vítima e seu advogado tinham receio de que alguém do hospital pudesse ter acesso a esta pesquisa e, mesmo com os nomes verdadeiros não divulgados, reconhecesse o caso, desfazendo o acordo.

Outra instância acessada foi o Judiciário - aqui se leia Tribunal de Justiça, Ordem dos Advogados Brasileiros, Varas, Câmaras e Fóruns -, que não fez um mínimo de esforço para saber do que tratava a pesquisa. Reforça-se que os caminhos éticos foram respeitados, e não se mediu esforço para chegar aos advogados de pessoas vítimas de erros médicos, no caso de processos já julgados, ou para que a existência da pesquisa fosse do conhecimento dos advogados especialistas da área de saúde inscritos na Ordem de São Paulo. Entretanto, nenhuma solicitação do pesquisador foi sequer respondida.

Tentou-se uma possibilidade de parceria com o Conselho Regional de Medicina do Estado de São Paulo (Cremesp). Mesmo sabendo da dificuldade, era uma tentativa que precisava ser feita. A resposta veio, informando que não era possível o Conselho auxiliar a pesquisa, segundo as normas éticas por ele estabelecidas.

Diante de tamanha dificuldade e limitações, abriu-se mão do critério de comprovação do erro médico para participar da pesquisa. A partir de então, casos com andamento na Justiça comum ou no Conselho puderam fazer parte deste estudo. Aqui, o pesquisador tomou o cuidado de tentar analisar casos em que possivelmente o erro estaria explícito, mesmo não sendo um técnico da área e nem tendo o julgamento final do processo. Posto isso, a Defensoria Pública do Estado de São Paulo foi procurada, e os funcionários prontamente auxiliaram na demanda da pesquisa.

Ainda assim, o número de participantes era insuficiente, e a última possibilidade foi incluir os casos de erros médicos da cidade do Rio de Janeiro, com ajuda da ONG Avermes (Associação das Vítimas de Erros Médicos). Essa decisão foi tomada com segurança, pois não havia barreiras que infringissem ou destoassem do objetivo inicial do estudo. Logo, nenhum prejuízo colocaria em risco a finalidade do trabalho, pois a subjetividade, a singularidade e o sofrimento psíquico de cada experiência vivida eram o que de fato interessava.
É claro que, ao realizar uma pesquisa científica no País, o pesquisador está sujeito a determinadas dificuldades em diversas etapas. E aqui o pesquisador não se exime dessa parcela, haja vista que as dificuldades estavam previstas. $\mathrm{O}$ que se quer ressaltar é a enorme complexidade e falta de humanidade por parte de representantes legais públicos e privados em relação a uma pesquisa científico-acadêmica, com rigor teórico e ético, a ser desenvolvida no Brasil. E, também, expor cientificamente esses percalços, na tentativa de impulsionar discussões sobre dificuldades metodológicas na área da saúde.

Fica claro que os resultados apresentados neste trabalho farão referência a uma pequena amostra que o pesquisador conseguiu atingir, pois, diante dos fatos expostos, é notória a falta de conhecimento do que a pesquisa científica pode gerar para um país e, também, o quanto é penosa, complexa e fechada a tentativa de chegar até os casos de erros médicos e tentar uma parceria com as outras áreas, como a medicina, o jornalismo e o direito, impedindo, talvez, a divulgação da verdade sobre o sofrimento psíquico dessas vítimas de erro médico. Vale lembrar que não se trata de um apelo para comoção e pena do pesquisador, mas, sim, da necessidade de esclarecer a realidade encontrada no campo de pesquisa ao se trabalhar com a temática erro médico no Estado de São Paulo.

\section{REFERÊNCIAS}

1. Gomes JCM, Drumond JGF, França GV. Erro médico. Montes Claros: Ed. Unimontes, 2001.

2. Rosa MB, Perini E. Erros de medicação: quem foi? Revista da Associação Médica Brasileira 2003;49(3):335-341.

\section{CONFLITO DE INTERRESSES}

O autor declara não haver conflito de interesses.

\section{ENDEREÇO PARA CORRESPONDÊNCIA}

Vitor Silva Mendonça

Av. Prof. Mello Moraes, 1721

Cidade Universitária - São Paulo

CEP 05508-030 - SP

E-mail: vitor.pospsico@bol.com.br 